\title{
EL REGISTRO ESPECIAL DE BUQUES DE CANARIAS
}

\author{
MARÍA DEL PINO DOMÍNGUEZ CABRERA \\ Profesora Asociada de Derecho Mercantil \\ Universidad de Las Palmas de Gran Canaria
}

SUMARIO

1.- INTRODUCCIÓN. 2.-.APROXIMACIÓN GENERAL A LOS SEGUNDOS REGISTROS DE BUQUES. 3.- REGISTRO ESPECIAL DE BUQUES Y EMPRESAS NAVIERAS DE CANARIAS: 3.1.-REGULACIÓN Y ÓRGANOS COMPETENTES. RASGOS PRINCIPALES Y FINALIDAD. 3.2.- BUQUES, EMBARCACIONES Y ARTEFACTOS NAVALES REGISTRABLES. 3.3.- CONTENIDO Y EFECTOS DE LA INSCRIPCIÓN. 4.- CONCLUSIONES. - BIBLIOGRAFÍA CITADA.

\section{RESUMEN}

Este trabajo aborda el estudio del Registro Especial de Buques y Empresas Navieras de Canarias (REBECA) como único segundo registro marítimo español. Se trata de un registro adicional al Registro Marítimo ordinario que reúne además las características de especial, público y administrativo, opcional, heterónomo, y selectivo. Más específicamente, concentra su atención en el objeto registral pues, como el título indica, se ocupa exclusivamente del Registro de Buques, pero no de la inscripción de las empresas marítimas o navieras, aunque la Ley de Puertos del Estado y de la Marina Mercante también contemple la inscripción de los empresarios navieros. Además, se examina el registro de embarcaciones y artefactos sin proceder a un análisis pormenorizado de las titularidades, cargas, gravámenes y limitaciones que encuentran cabida en el asiento registral practicado en el Registro Especial. 


\section{1.- INTRODUCCIÓN}

Desde un punto de vista terminológico y funcional, la institución tradicional del Registro de buques y el fenómeno particular de los segundos registros exige establecer diferencias entre lo que podemos denominar el Registro marítimo nacional clásico y los segundos registros de buques. Estos últimos pueden ser registros situados en territorios o posesiones de ultramar (registros off-shore), o bien segundos registros de carácter especial y situados dentro del propio territorio estatal, continental o insular, como ocurre en el caso español con el Registro Especial de Buques y Empresas Navieras de Canarias (en adelante REBECA).

El Registro marítimo nacional clásico de buques admite las modalidades siguientes:

a) bien un sistema de registro unitario, que correspondería a los países que han optado por inscribir los buques que enarbolan su pabellón en un Registro único, el cual produce efectos jurídico-públicos y jurídico-privados. Este es el caso del Registro Público Marítimo Nacional de México ${ }^{1}$, del Registro Nacional de Buques de Argentina $^{2}$, o del Registry of Shipping and Seamen del Reino Unido de Gran Bretaña e Irlanda del Norte, entre otros.

b) bien un sistema de registro doble, por cuanto el buque es inscrito en un registro administrativo que produce básicamente efectos jurídico públicos pero accede igualmente a un registro mercantil con efectos jurídico-privados, siendo este sistema la opción de nuestro Derecho positivo. Efectivamente, el sistema español de registro de buques es básicamente doble, porque junto al Registro Marítimo ordinario, de carácter público y administrativo y con efectos básicamente jurídico públicos, existe un Registro de Bienes Muebles (RBM) integrado por seis secciones, la primera de las cuales tiene por objeto el registro de buques y aeronaves. El RBM tiene carácter mercantil y tiene efectos jurídicos privados, quedando sujeto básicamente a las normas contenidas en el Reglamento del Registro Mercantil de 1956, en la Orden del Ministerio de Justicia de 19 de julio de 1999 por la que se aprueba la Ordenanza para el Registro de Venta a Plazos de bienes Muebles y en el R.D. 1828/1999 de 3 de diciembre por el que se aprueba el Reglamento del Registro de condiciones generales de la contratación ${ }^{3}$.

Sea uno u otro el sistema registral de buques establecido, pueden tratarse de sistemas abiertos o cerrados según que se permita o se restrinja el acceso al registro de los buques que no son propiedad de personas físicas o jurídicas nacionales del Estado de registro.

\footnotetext{
${ }^{1}$ Cfr. ENRIQUEZ ROSAS, DAVID: El buque: una introducción al estudio del estatuto jurídico de las embarcaciones, México, 1998, pp. 389 y ss.

${ }^{2}$ Cfr. RAY, JOSÉ DOMINGO: Derecho de la navegación, vol. I, Buenos Aires, 1992, pp. 352-362, así como GONZÁLEZ LEBRERO, RODOLFO: Manual de Derecho de la Navegación, Buenos Aires, 2000, pp. 124 y 132.

${ }^{3}$ Sobre ello, vid., DOMÍNGUEZ CABRERA, MARIA DEL PINO: «El buque como objeto del Registro de Bienes Muebles», Noticias Jurídicas, sección de Artículos doctrinales, febrero 2004, en la dirección URL: http://www.noticiasjuridicas.com.
} 
Los segundos registros nacionales, por su localización geográfica, pueden ser registros ubicados en territorios o posesiones de ultramar, pudiendo calificarse de registros off-shore, tal es el caso del segundo registro del Territorio antártico francésIslas Kerguelen o el segundo registro británico de las Islas Malvinas; o bien tratarse de registros especiales, que corresponderían a los segundos registros situados dentro del territorio estatal, continental o insular, caso del REBECA ${ }^{4}$, del Madeira Ship Registry (MAR), Novegian International Ship Register (NIS), German International Ship Register (ISR) o del Registro internazionale italiano; y que quedan sujetos a un régimen jurídico diferenciado respecto al régimen ordinario aplicable al Registro marítimo nacional clásico. Como para el registro marítimo nacional clásico, estos segundos registros pueden adoptar un modelo abierto o cerrado según se permita o impida el registro de buques que no son propiedad de personas físicas o jurídicas nacionales del Estado en cuyo segundo registro se pretende la inscripción.

\section{2.- APROXIMACIÓN GENERAL A LOS SEGUNDOS REGISTROS DE BUQUES}

Ante el retraimiento considerable de la flota mercante registrada en algunos países europeos constatada desde comienzos de la década de los años 80, algunos países idearon la creación de segundos registros de buques a fin de conceder ventajas o beneficios a quienes inscribieran en ellos sus buques, básicamente con el objeto de combatir el fenómeno de las Banderas de Conveniencia (BdC) y la competencia desleal derivada de los costes laborales y fiscales inferiores de los registros abiertos ${ }^{5}$. Para referirse a este fenómeno se han empleado distintas expresiones, aparte de la de

\footnotetext{
${ }^{4}$ En este sentido, CARLIER DE LAVALLE, MANUEL: «El Registro Especial de Canarias. Ventajas y situación hoy», Asociación de Navieros Españoles, Ponencia del Director General de ANAVE, Tenerife, 2628 de septiembre de 2002 (extraído de la página web de ANAVE, dirección URL: http://www.anaves.es/Informes), p. 6.

${ }^{5}$ Un pabellón de conveniencia, en sentido funcional, es el propio de países que abren sus registros a buques que, o bien son propiedad de extranjeros, o bien están bajo su control, en condiciones tales que, cualquiera que sean los motivos, son convenientes y oportunas para las personas que registran esos buques. Según Boczek, «functionally, a "flag of convenience" can be defined as the flag of any country allowing the registration of foreign-owned and foreign-controlled vessels under conditions which, for whatever reasons, are convenient and opportune for the persons who are registering the vessels». Cit. por READY, N. P.: Ship Registration, LLP Publisher, London-Hong Kong, third edition, 1998, p. 17 (la definición procede de la obra de Boczek titulada Flags of convenience-An International legal study, Harvard University Press, 1962). De ahí que también se aluda al fenómeno utilizando expresiones como las de sistemas o registros abiertos, o buques de libre matrícula V. SAN JOSÉ AMÉZAGA, JAVIER: «Segundos registros de buques», en EIZAGUIRRE, JOSÉ MARÍA DE (Coordinador): IV Jornadas de Derecho Marítimo de San Sebastián (San Sebastián, 23 y 24 de mayo de 1996), 1997, p.64. ENRIQUEZ ROSAS, DAVID: El buque: una introducción al estudio del estatuto jurídico de las embarcaciones, cit., p. 173-176, entendiéndose fácilmente que se trate de países cuyos nacionales tienen poco o nulo interés y tradición en el tráfico naval GRIME, ROBERT: Shipping Law, Sweet and Maxwell, Concise College Texts, second edition, London, 1991, p. 31., y que los buques así registrados rara vez estén sujetos a la jurisdicción del Estado de registro o lleguen a atracar en sus puertos. En efecto, el profesor Hill señala que la expresión "flags of convenience" alude a «the registering of ships under the flag of certain States when they are in fact beneficially owned and controlled by nationals of other countries manned by foreign crews and seldom, if ever, enter the jurisdiction or ports of their country of registry». HILL, CRISTOPHER: Maritime Law, Lloyd's of London Press, Lloyd's Practical Shipping Guides, London, Hong Kong, fifth edition, 1998, p. 9. Esto último, entre otros factores, sirve para dudar de la existencia de una relación auténtica entre el buque y el Estado del registro.
} 
segundos registros: registro internacional, registro secundario, registro extraterritorial o banderas de necesidad.

Los primeros registros de este tipo se constituyeron en Francia (Islas Kerguelen, en 1987), Noruega (Registro Internacional de Buques de Noruega, NIS ${ }^{6}$, en 1987), Dinamarca (Registro internacional de buques de Dinamarca, DIS, en 1988), Portugal (Madeira, MAR, en 19897) y Alemania (Registro Internacional de Buques de Alemania,

\footnotetext{
${ }^{6}$ El caso de Noruega es ilustrativo de las causas que motivaron la aparición de los segundos registros. En un periodo de cinco años la flota registrada en Noruega experimentó un descenso superior al $75 \%$. Ello llevó a lo que ha sido calificado como una respuesta visionaria de las autoridades noruegas al fenómeno de las Banderas de Conveniencia (BdC), al ofrecer un registro cualificado -el Norvegian International Ship Register (NIS)- que sin embargo, fuera capaz de conciliar los convenios internacionales ratificados por el país y su reputación de potencia marítima responsable con el otorgamiento de determinadas ventajas en cuanto a costes y fiscalidad. Aunque se trata de un registro abierto a propietarios extranjeros, estaba principalmente dirigido a lograr el regreso a un registro noruego de los propietarios noruegos que en los años anteriores habían abandonado el pabellón nacional. En este sentido, el NIS obtuvo un éxito notable en un breve período de tiempo, ya que en tres años la flota nacional alcanzó niveles superiores a los que existían antes del señalado éxodo. Los principales elementos del NIS son los siguientes: a) inexistencia de restricciones por razón de la nacionalidad en cuanto a la tripulación del buque o su propiedad; b) libertad para negociar salarios y otras condiciones de empleo con los representantes sindicales de cualquier nacionalidad; c) inexistencia de condiciones para el establecimiento de las sociedades en Noruega, siempre y cuando el representante y parte de las operaciones de funcionamiento se localicen en Noruega; y d) no sujeción de los propietarios extranjeros a tasas. Cfr. SAN JOSÉ AMÉZAGA, JAVIER: «Segundos registros de buques», EIZAGUIRRE, JOSÉ MARÍA DE (Coordinador): IV Jornadas de Derecho Marítimo de San Sebastián (San Sebastián, 23 y 24 de mayo de 1996), cit., p. 86, así como FARTHING, BRUCE y BROWNRIGG, MARK: Farthing on International Shipping, London-Hong Kong, third edition, 1997, pp. 189.

${ }^{7}$ La implantación del segundo registro de buques portugués por medio del Decreto-Lei no 96/89 de 28 de marzo (Diário da República, $\mathrm{n}^{\circ} 72$, de 28-3-1989) obedece igualmente a la voluntad de dar una respuesta a la crisis internacional del sector como consecuencia del abanderamiento de buques en países con BdC. Se trataba así de imprimir un mayor dinamismo económico a la Marinha de comércio nacional portuguesa; pero también a la Región autónoma de Madeira (cfr. párrafos 8 y 10 de la Exposición de motivos del mencionado Decreto ley). El nuevo Registro creado se denomina Registo Internacional de Navios da Madeira, abreviadamente denominado MAR, el cual se inserta en la Conservatória do Registo Comercial propio de la zona franca de Madeira. Con posterioridad, el citado Decreto Ley se ha visto afectado por las siguientes disposiciones: Decreto-Lei $n^{\circ}$ 393/93, de 23 de noviembre (Diário da República, no 274, de 23-11-1993), Decreto-Lei no 5/97, de 9 de enero (Diário da República, no 7, 9-1-1997), Decreto-Lei no 31/97, de 28 de enero (Diário da República, no 23, 28-1-1997), Decreto-Lei no 331/99, de 20 de agosto (Diário da República, $\mathrm{n}^{\circ}$ 194, 20-8-1999) y, más recientemente, el Decreto-Lei $\mathrm{n}^{\circ}$ 248/2002, de 8 de noviembre (Diário da República, $\mathrm{n}^{\mathrm{o}}$ 258, de 8-11-2002).
}

El MAR funciona bajo la autoridad de los Ministérios da Justiça e do Mar y tiene por objeto el registro de todos los actos y contratos relativos a los buques y a los sujetos, así como el control de los requisitos de seguridad exigidos por las convenciones internacionales aplicables. Más concretamente, el registro de buques depende del primero de los ministerios citados, mientras que el Ministerio del mar supervisa lo relativo a la seguridad de la navegación, protección de la vida humana en el mar y del medio ambiente marino, así como fiscalizar los aspectos técnicos de los buques registrados en el MAR (artículo $1^{\circ}$ del Decreto-Lei $\mathrm{n}^{\circ}$ 96/89).

Por buque (navio) se entiende cualquier embarcación de comercio o recreo que opere en el medio ambiental marino, incluyendo las plataformas fijas o móviles, las embarcaciones auxiliares y los remolcadores (artículo $5^{\circ}$, apdo. e). Además se establece expresamente que los buques registrados en el MAR enarbolarán el pabellón portugués (artículo 6².2).

A tenor de lo dispuesto por el artículo 15, podrán ser objeto de inscripción en el MAR los buques propiedad de:

a) Entidades cuya actividad se desarrolla en el ámbito institucional de la zona franca de Madeira. Son aquéllas cuya constitución y funcionamiento han sido debidamente autorizados por el Gobierno regional de Madeira y que realizan actividades propias de la industria del transporte marítimo o de la marina de recreo, en la región autónoma de Madeira. Para obtener esa autorización se requiere la obtención de una licencia de 
ISR, en 1989). La puesta en funcionamiento de tales registros supuso que un gran número de buques, cuya propiedad beneficiaria pertenecía a estos países, retornase al registro del país con el que tenían en realidad un vínculo más profundo e intenso, produciendo entonces el cese de la BdC.

A esta proliferación inicial de creación de nuevos segundos registros sucedió un periodo de calma, del que nosotros debemos sin embargo destacar la promulgación en el año 1992 de la Ley de Puertos del Estado y de la Marina Mercante (LPEMM 1992), cuya Disposición adicional $15^{\mathrm{a}}$ creó el Registro Especial de Buques y Empresas Navieras de Canarias (REBECA). A partir de 1997, se ha observado un repunte de este fenómeno, ya que diversos países europeos entre los que figura Italia ${ }^{8}$, instauraron sus

instalación y de una licencia anual de funcionamiento (artículos $15^{\circ}$.1.a y $8^{\circ}$ ). Tales entidades no están obligadas a tener en Madeira su sede social (artículo $11^{\circ} .1$ ), si bien deberán tener en Madeira una sucursal, delegación, agencia o cualquier otra forma de representación dotada de todos los poderes necesarios para asegurar una representación plena ante las autoridades estatales o regionales y ante terceros, debiendo designar un domicilio particular al efecto. Tales poderes incluirán obligatoriamente el de recibir citaciones (artículo $11^{\circ}$, apdos. 2 y 3 ).

b) Entidades que no forman parte del ámbito institucional de la zona franca de Madeira (artículo 15.1.b).

Se contempla asimismo el abanderamiento provisional en el MAR (flagging in) de buques tomados por las entidades antes señaladas bajo contrato de fletamento a casco desnudo, siempre que hayan sido debidamente autorizadas por sus propietarios y por las autoridades competentes del Estado donde figure inscrita la propiedad (artículo $15^{\circ} .2$ ). El artículo 18 permite al MAR autorizar el registro provisional en el extranjero de buques fletados a casco desnudo (flagging out).

Las entidades off-shore reseñadas en el artículo $15^{\circ} .1$ a) que soliciten la inscripción, habrán de aportar: autorización de la Región autónoma de Madeira, título de adquisición del buque o contrato de fletamento a casco desnudo y liquidación de las tasas exigidas para la obtención de la licencia de instalación y la licencia anual de funcionamiento (artículo $17^{\circ} .1$ ).

Por su parte, las demás entidades referidas en el artículo $15^{\circ} .1 . b$ (aquéllas que no forman parte del ámbito institucional de la zona franca de Madeira) deberán aportar la indicación de la firma o denominación social, domicilio o sede del requirente, y si fuera un empresario social, el contrato social correspondiente. Si fuera una persona física, su identificación completa. Finalmente, también debe aportarse el título de adquisición del buque o contrato de fletamento a casco desnudo (artículo $17^{\circ} .2$ ). En cualquier caso, si el domicilio o sede de las entidades de uno y otro tipo (que se dediquen al transporte marítimo o la marina de recreo) se encontrara situado fuera de la región autónoma de Madeira, deberán cumplirse los requisitos de los números 2 y 3 del artículo $11^{\circ}$, antes señalados (artículo $17^{\circ} .3$ ).

Por último, varias disposiciones del Decreto-Lei 96/89 contemplan el tipo de navegación (artículos 4 y $15^{\circ}$ ) y las exigencias relativas a la tripulación y dotación de los buques registrados en el MAR. El artículo $20^{\circ}$ dispone a este respecto que el comandante y al menos el 50\% de la tripulación de los buques inscritos en el MAR deben ser ciudadanos de nacionalidad portuguesa o nacionales de países de europeos o países de lengua oficial portuguesa; si bien en casos especiales debidamente justificados, cuando no fuera posible el reclutamiento de marinos nacionales de los países antes señalados, podrá autorizarse el embarque de marinos de otras nacionalidades más allá del límite del 50\%. Sin embargo, esas exigencias no afectan a las embarcaciones de recreo (apdos. 1, 2 y 3 del artículo $20^{\circ}$ del Decreto-Lei 96/89, tras las modificaciones introducidas por el Decreto-Lei n ${ }^{\circ}$ 248/2002, de 8 de noviembre.

${ }^{8}$ El denominado Registro internazionale italiano fue creado en virtud del Decreto ley $\mathrm{n}^{\mathrm{o}} 457$, de 30 de diciembre de 1997, aprobándose por Decreto del Ministerio de Transportes de 28 de febrero de 1998, los modelos de certificados (llamados atto di nazionalità) del nuevo registro. La principal finalidad consistía en estimular a los armadores italianos a abandonar las $\mathrm{BdC}$ facilitándoles, como contrapartida, el reclutamiento de marineros de otra nacionalidad. Si bien se pensó en establecer el Registro internazionale únicamente en los principales puertos italianos, finalmente el Ministerio mencionado antes optó por la implantación del Registro internazionale en todos los puertos italianos en los que existe un registro de buques. El nuevo Registro internazionale consta de tres secciones y, en cualquier caso, sólo tienen acceso al mismo los buques empleados exclusivamente en el comercio internacional, de manera que el registro está vedado a los buques destinados al comercio entre puertos italianos, el cual queda reservado por virtud del artículo 224 del Codice 
propios segundos registros. De esta manera, según un informe de la Organización Internacional del Trabajo (OIT), en la actualidad los países indicados en el Cuadro siguiente poseen segundos registros:

\section{$\underline{\text { Cuadro - Países con segundos registros de buques }}^{9}$}

\begin{tabular}{ll}
\hline PAÍSES & \multicolumn{1}{c}{ SEGUNDOS REGISTROS } \\
\hline Brasil & Registro Especial Brasileiro (REB) \\
China & Hong Kong \\
& Macao \\
& Registro Internacional de Dinamarca (DIS) \\
Dinamarca & Islas Feroe \\
& Islas Feroe (FAS) \\
& Territorio antártico francés-Islas Kerguelen \\
& Islas Wallis y Futuna \\
& Registro Internacional de Buques de \\
& Alemania (GIS o ISR)
\end{tabular}

della Navigazione a armadores comunitarios que operen buques inscritos en un registro de un Estado miembro de la UE, siempre y cuando se cumplan las condiciones exigidas en el Estado de registro para la realización del cabotaje. En la primera pueden ser inscritos los buques en los que la mayoría de sus partes (carati) sean propiedad de personas físicas o jurídicas de nacionalidad italiana o de alguno de los Estados miembros de la UE. A la segunda sección tienen acceso los buques propiedad de personas físicas o jurídicas cuya nacionalidad sea extrtacomunitaria, cumpliendo determinados requisitos que fija el artículo 147 del Codice della Navigazione. Por último, en la tercera sección son susceptibles de inscripción los buques de pabellón extranjero fletados a casco desnudo (bareboat charter) a personas o sociedades italianas o comunitarias, con suspensión temporal del pabellón originario. Sobre el Registro internazionale italiano v. BERLINGIERI, FRANCESCO: «The new Italian international ship register», Lloyd's Maritime and Commercial Law Quarterly, Part 4, November 1998, pp. 535 y ss.; MARCHESE, UGO: «Funcione economica e politica fiscale del "registro internazionale" italiano di immatricolazione navale», Trasporti. Diritto, Economia, Politica, no 77-78, 1999, pp. 65 y ss.; ODEKE, ADEMUNI: Bareboat Charter (Ship) Registration, The Hague/London/Boston, 1998, pp. 525-527.

${ }^{9}$ Fuente: ORGANIZACIÓN INTERNACIONAL DEL TRABAJO: El impacto en las condiciones de vida y de trabajo de la gente de mar de los cambios en la estructura de la industria naviera (Informe para el debate de la 29. a reunión de la Comisión Paritaria Marítima), Doc. JMC/29/2001/3, Oficina Internacional del Trabajo, Ginebra, 2001, p. 21. Este informe de la OIT considera como registros no activos, debido a sus operaciones y a su significación internacional, a los siguientes: Islas de Wallis y Futuna, Islas Cook, Macao, Anguila, Islas Vírgenes británicas, Islas del Canal, Islas Malvinas y las Islas Turcos y Caicos. Se trata de registros muy pequeños y que reflejan incrementos muy escasos o nulos, registrándose en ellos barcos pequeños. Ibíd., p. 20. 
Italia Segundo Registro

Países Bajos Antillas Neerlandesas

Nueva

Zelanda

Islas Cook

Noruega Registro Internacional de Buques de

Noruega (NIS)

Portugal Madeira (MAR)

España Islas Canarias (REC)

Turquía Segundo Registro

Anguila

Bermudas

Islas Vírgenes británicas

Islas Caimán

Reino Unido Islas del Canal

Islas Malvinas (Falkland Islands)

Gibraltar

Isla de Man

Islas Turcos y Caicos

Entre las motivaciones que explican la implantación de esos y otros segundos registros ${ }^{10}$, como fenómeno de reacción de los países desarrollados al fenómeno de las BdC, cobran importancia las de naturaleza económica, dado que las autoridades estatales consintieron en ello, no sólo con la finalidad de competir con los registros de libre matrícula y frenar así el éxodo de su flota hacia las BdC, sino también para promover la exención de tributos y cargas fiscales y sociales generados por el empleo de

\footnotetext{
${ }^{10}$ Ademuni Odeke añade a esta relación de segundos registros del Reino Unido de Gran Bretaña los siguientes: Territorio británico antártico, Territorio británico en el Océano Indico, Guernsey, Jersey, Montserrat, Islas Pitcairn, Saint Helen y Dependencias y las Areas soberanas de Akrotiri y Dhekelia (en Chipre). ODEKE, ADEMUNI: Bareboat Charter (Ship) Registration, cit., p. 34. Asimismo, refiere la creación por otros países de nuevos registros: Luxemburgo, en el año 1990, creó un sistema registral para buques de más de 25 TRB y menos de 15 años; mientras que Japón en 1996 aprobó una ley para la creación de un registro internacional destinado a la venta, arrendamiento y fletamento de buques de pabellón japonés a intereses extranjeros. Ibíd., pp. 33 y 34.
} 
marineros nacionales, así como permitir a los armadores libertad contractual para el reclutamiento de mano de obra (tripulación) procedente de países del denominado tercer mundo, cuyas condiciones laborales no son las de la legislación estatal.

En tal sentido, los segundos registros son una vía indirecta para el subsidio y mantenimiento de la flota de pabellón nacional ${ }^{11}$. Se ha dicho también que su constitución responde a una necesidad impuesta «por las propias exigencias del tráfico marítimo mundial» y que «desde siempre se ha visto la necesidad de implantar un sistema legal autónomo, al margen del excesivo intervencionismo de las Administraciones nacionales en sus respectivas Marinas Mercantes» ${ }^{12}$.

Además, aparte de ser ciertas las ventajas que reportan los segundos registros al permitir la reducción en general de los costes de la explotación de los buques, ello influye en la calidad de la mano de obra utilizada a bordo siempre y cuando tales registros conlleven el reclutamiento de tripulación de la nacionalidad del registro, más experimentada que la que emplean las $\mathrm{BdC}^{13}$, lo que repercute a su vez en la reducción de su siniestralidad. En este sentido, la seguridad y calidad de los segundos registros de buques ha sido analizada con el fin de establecer una relación entre la accidentalidad de los buques y factores de calidad como la formación de la tripulación, equipamiento, etcétera. Así, se confirma que aunque la tasa de accidentes es mayor en buques de segundos registros, progresivamente su seguridad va claramente en aumento ${ }^{14}$.

Sin embargo, hay que precisar que no todos los segundos registros operan del mismo modo en cuanto a los buques que pueden acceder a la inscripción, ya que mientras unos países admiten tanto buques de la nacionalidad propia como buques extranjeros (denominándose entonces registro internacional), otros Estados han preferido reservar su segundo registro para buques que enarbolan su propio pabellón ${ }^{15}$. Además, desde el punto de vista de su localización geográfica, mientras que algunos Estados que disponen de posesiones o territorios de ultramar, vestigios de su pasado colonial, han situado aquí sus segundos registros de buques; otros que carecen de tales dominios no han tenido otro remedio que establecer su segundo registro dentro de su

\footnotetext{
${ }^{11}$ Sobre los segundos registros de buques en general, cfr. SAN JOSÉ AMÉZAGA, JAVIER: «Segundos registros de buques», cit., pp. 85-88; ARROYO MARTÍNEZ, IGNACIO: «Reflexiones en torno a la Ley de Puertos del Estado y Marina Mercante», Anuario de Derecho Marítimo, volumen XI, 1994, pp. 79-84; FARTHING, BRUCE y BROWNRIGG, MARK: Farthing on International Shipping, cit., pp. 189-191; ODEKE, ADEMUNI: Bareboat Charter (Ship) Registration, cit., 1998, pp. 31-34; ORGANIZACIÓN INTERNACIONAL DEL TRABAJO: El impacto en las condiciones de vida y de trabajo de la gente de mar de los cambios en la estructura de la industria naviera, cit., pp. 20-26; READY, N. P.: Ship Registration, cit., pp. 29-33.

${ }_{12}$ Palabras pronunciadas por el Sr. Juan Carlos Atxa, Presidente de la Asociación de Navieros Vascos durante la Mesa Redonda sobre los segundos registros de buques, celebrada durante las IV Jornadas de Derecho Marítimo de San Sebastián. EIZAGUIRRE, JOSÉ MARÍA DE (Coordinador): IV Jornadas de Derecho Marítimo de San Sebastián, cit., p. 98.

${ }^{13}$ ORGANIZACIÓN INTERNACIONAL DEL TRABAJO: El impacto en las condiciones de vida y de trabajo de la gente de mar de los cambios en la estructura de la industria naviera, cit., p. 24.

${ }^{14}$ Cfr. en este sentido LI, K.X.: «The safety and quality of open registers and a new approach for classifying risky ships», Logistics and Transportation Review, vol. 35E, nº 2, june 1999, pp. 135 y ss.

15 ARROYO MARTÍNEZ, IGNACIO: «Reflexiones en torno a la Ley de Puertos del Estado y Marina Mercante», Anuario de Derecho Marítimo, volumen XI, 1994, en nota número 53, a pie de p. 83.
} 
propio territorio (sea éste continental, sea éste insular o incluso insular ultraperiférico, como es el caso del Archipiélago Canario).

Todo ello no impide que los segundos registros hayan sido blanco de críticas procedentes principalmente de organizaciones que actúan en el ámbito laboral. La OIT se ha ocupado repetidamente de la evolución del registro naval. En la Conferencia Internacional del Trabajo que se reunió en Ginebra, en junio de 1991, se puso por ejemplo en evidencia el modo en que el DIS danés vulnera los derechos consagrados en los Convenios de la OIT 87, 98, y $111^{16}$, críticas que se han reiterado en subsiguientes reuniones de la organización. Además, la utilización de los territorios no metropolitanos para la implantación de nuevos segundos registros ha traído desventajas que han llevado al Gobierno francés a considerar la posible constitución de un nuevo registro nacional en su territorio metropolitano para sustituir al segundo registro de las Islas Kerguelen ${ }^{17}$.

Las organizaciones profesionales y sindicales de los marinos han expresado también su oposición a estos registros, toda vez que el empleo de extranjeros afecta a la mano de obra local, o bien obliga a los nacionales a aceptar condiciones de trabajo desfavorables. En tal sentido, la Federación Internacional de los Trabajadores del Transporte (ITF) ha alertado a los armadores sobre las consecuencias de cambiar las tripulaciones, determinando que tal actitud implicaría considerar al registro como una simple BdC. Así, teniendo en cuenta el alto grado de desreglamentación que existe en los segundos registros, la ITF ha concluido que trece de ellos deberían ser calificados realmente como BdC. Se trata de los segundos registros situados en las Antillas Neerlandesas, Bermudas, el DIS danés, Gibraltar, el ISR alemán, Hong Kong, Isla de Man, Islas Caimán, Islas Canarias, Islas Cook, Islas Kerguelen, el MAR portugués y el NIS noruego ${ }^{18}$. Sin embargo, el $40^{\circ}$ Congreso de la ITF, reunido en Vancouver entre el 17 y el 21 de agosto de 2002, aprobó una moción que acordó el levantamiento de la consideración del REBECA como $\mathrm{BdC}^{19}$.

\footnotetext{
${ }^{16}$ Convenio sobre la libertad sindical y la protección del derecho de sindicación, 1948 ( $N^{\circ} 87$ ), Convenio $\left(\mathrm{N}^{\circ}\right.$ 98) relativo a la aplicación de los principios del derecho de sindicación y de negociación colectiva. Adoptado el 1. de julio de 1949 por la Conferencia General de la Organización Internacional del Trabajo en su trigésima segunda reunión. Entrada en vigor: 18 de julio de 1951. Convenio relativo a la discriminación en materia de empleo y ocupación, 1958 (N 111) Fecha de entrada en vigor: 15.06.1960.

${ }^{17}$ ORGANIZACIÓN INTERNACIONAL DEL TRABAJO: El impacto en las condiciones de vida y de trabajo de la gente de mar de los cambios en la estructura de la industria naviera, cit., p. 21. Por su parte, países como Bélgica ha modificado su registro nacional de buques, que estaba basado en un sistema altamente subvencionado lo que había provocado que la totalidad de su flota abandonara el pabellón nacional, optando por el pabellón luxemburgués y que era conocido como el segundo registro belga. El nuevo régimen está basado en un impuesto sobre tonelaje (tonnege tax) y en incentivos a la inversión. Cfr. Tribuna Profesional de ANAVE: "Normativa", Boletín Informativo de la Asociación, $\mathrm{n}^{\circ}$ 415, junio 2003, p. 30, Dirección URL: http://www.anave.es.

${ }^{18} \mathrm{Cfr}$. la ITF en la dirección URL: http://www.itf.org.uk

${ }^{19}$ La moción, propuesta por la Federación Estatal de Transportes, Comunicaciones y Mar del Sindicato Unión General de Trabajadores decía así:

«El $40^{\circ}$ Congreso de la ITF, reunido en Vancouver del 14 al 21 de agosto de 2002:

1. CONSIDERANDO que el Registro Especial de Buques de las Islas Canarias ha sido dotado de legislación e instrumentos suficientes para garantizar las condiciones de los trabajadores en materia laboral, económica y de Seguridad Social.

2. (...) que tal situación ha provocado que la práctica totalidad de la flota mercante española se encuentre abanderada en el Registro Especial de Buques de las Islas Canarias, sin que ello haya repercutido de forma
} 


\section{3.- EL REGISTRO ESPECIAL DE BUQUES Y EMPRESAS NAVIERAS DE CANARIAS.}

\section{1.- Regulación y órganos competentes. Rasgos principales y finalidad.}

El REBECA es, hasta la fecha, el primer y único segundo registro nacional. $\mathrm{Su}$ creación se remonta al año 1992 y tiene su fundamento legal en la Disposición adicional decimoquinta de la LPEMM, si bien debemos precisar que fue necesario adoptar diversas medidas legislativas que permitieran completar los incentivos laborales previstos inicialmente en la LPEMM $^{20}$ con bonificaciones en materia fiscal y de seguridad social ${ }^{21}$.

negativa en las condiciones sociolaborales de los trabajadores, ni en la cobertura del régimen nacional de Seguridad Social de la que venían disfrutando.

3. (...) que el Registro Especial de Buques de las Islas Canarias se encuentra sometido a la legislación laboral española y las empresas abanderadas en el mismo sometidas a las exigencias contenidas en la misma, en materia de negociación colectiva y de representación sindical.

4. (...) que las empresas con buques abanderados en el Registro Especial de Buques de Canarias se encuentran sometidas a la inspección y control de las autoridades laborales administrativas y judiciales españolas al igual que cualquier otra empresa ubicada en España.

5. (...) que el Registro Especial de Buques de las Islas Canarias reconoce a los trabajadores, entre otras, las siguientes condiciones positivas:

a. Exención en un $50 \%$ de sus rentas de cara a las declaraciones fiscales anuales, lo que les proporciona un mayor ingreso económico neto mensual sin ninguna contrapartida.

b. Bases de cotización iguales a las del resto de los sectores productivos del Estado.

c. Igual cobertura en materia de Seguridad Social que al resto de los sectores productivos, lo que incluye: prestaciones por accidente, enfermedad, muerte, jubilación y desempleo entre otras.

d. Coeficientes reductores a la edad de jubilación en función de las zonas de navegación de los buques.

e. Plena cobertura de la legislación laboral española.

f. Tutela de las autoridades laborales, administrativas y judiciales españolas.

6. (...) que todos estos hechos han propiciado el paso pacífico de los buques al Registro Especial de Buques de las Islas Canarias, manteniéndose los convenios colectivos y las representaciones sindicales existentes en los mismos y favoreciendo la recuperación de flota controlada por armadores españoles que navegaba bajo pabellones de conveniencia.

7. (...) que los buques abanderados en el Registro Especial de Buques de las Islas Canarias se encuentran sometidos a igual régimen de inspección y control por parte de las autoridades marítimas españolas que los buques anteriormente registrados en el Registro Central de Buques.

8. (...) que el Registro Especial de Buques de las Islas Canarias ofrece condiciones y garantías sociolaborales a los trabajadores iguales o superiores a las de otras banderas con la condición de Primeros Registros que no cuentan con la condición de bandera de conveniencia.

9. (...) que, en función de todos los hechos expuestos, procede levantar al Registro Especial de Buques de las Islas Canarias la vitola de bandera de conveniencia en este Congreso.

10. SOLICITAMOS al $40^{\circ}$ CONGRESO que se acuerde el levantamiento de la consideración de bandera de conveniencia al Registro Especial de Buques de las Islas Canarias». Página web de la ITF: dirección URL: http://www.itf.org.uk

${ }^{20}$ Contemplados en la Disp. adicional 15a . Seis.a) (sobre dotaciones de los buques) y Siete (sobre la normativa laboral y de seguridad social aplicable a los trabajadores no nacionales). En virtud de la primera, aunque el capitán y el primer oficial de los buques inscritos en el REBECA habrán de tener la nacionalidad española, siendo el resto de la dotación de nacionalidad española o de algún otro Estado miembro de la CE, al menos en un 50\%, "no obstante (...) cuando no haya disponibilidad de tripulantes de nacionalidad española o de algún otro Estado miembro (...), cuando medien razones de viabilidad económica del servicio de transporte, o por cualquier otra causa que pudiera tener una incidencia fundamental en la existencia del 
La sede del REBECA se halla obviamente en Canarias, operando a través de las dos oficinas especiales de gestión y administración adscritas al Ministerio de Fomento (MdF), situadas en Las Palmas de Gran Canaria y en Santa Cruz de Tenerife e incardinadas en las Capitanías Marítimas respectivas ${ }^{22}$. No cabe, por lo tanto, considerarlo como registro off-shore, porque este calificativo -tal y como lo hemos empleado antes- corresponde más bien a los segundos registros que tienen su base territorial en una dependencia o posesión colonial de ultramar de una metrópoli. El REBECA se sitúa en una parte del territorio insular español del Océano Atlántico que, a pesar de estar alejado del territorio continental, forma parte integrante de su ámbito de soberanía territorial y no admite en el Derecho internacional público la calificación de territorio colonial ${ }^{23}$. En todo caso, cabría calificarlo como segundo registro

servicio, el Ministerio (...) podrá autorizar a las Empresas solicitantes el empleo de tripulantes no nacionales de los Estados miembros (...) en proporción superior a la expresada anteriormente, siempre que quede garantizada la seguridad del buque y la navegación". Por su parte, la sección Siete de la citada Disp. adicional permite que las condiciones laborales y de seguridad social de los trabajadores no nacionales españoles empleados a bordo de esos buques se regulen por "la legislación a la que libremente se sometan las partes, siempre que la misma respete la normativa emanada de la Organización Internacional del Trabajo o, en defecto de sometimiento expreso, por lo dispuesto en la normativa laboral y de Seguridad Social española, todo ello sin perjuicio de la aplicación de la normativa comunitaria y de los convenios internacionales suscritos por España”.

${ }^{21}$ De esta forma, la legislación reguladora del REBECA resulta de las siguientes disposiciones:

1.- La señalada LPEMM, con sus sucesivas modificaciones posteriores.

2.- El R.D. 897/1993, de 11 de junio, que autoriza inscripción de buques y empresas destinados al tráfico de cabotaje.

3.- El R.D. 392/1996, de 1 de marzo, que autoriza la inscripción de empresas y buques destinados al tráfico de cabotaje de mercancías de interés estratégico.

4.- La Ley 13/1996, de 30 de diciembre, Medidas fiscales, administrativas y del orden social.

5.- El R. D. 2221/1998, de 16 octubre, autoriza la inscripción de empresas y buques destinados a la navegación marítima de cabotaje en el Registro Especial de Buques y Empresas Navieras.

6.- Ley 19/1994 de 6 de julio de modificación del Régimen Económico y Fiscal de Canarias, el R.D. Ley 3/1995, de 26 de Enero, de reforma parcial de la Ley 19/1994 , así como las modificaciones introducidas por el R.D. Ley $7 / 1998$.

7.- Ley 53/2002, de 30 de diciembre, de Medidas Fiscales, Administrativas y del Orden Social.

8.- Ley 10/2003, de 20 de mayo, de medidas urgentes de liberalización en el sector inmobiliario y transportes.

9.- Ley 48/2003, de 26 de noviembre, de régimen económico y de prestación de servicios de los puertos de interés general.

10.- Ley 62/03, de 30 de diciembre, de medidas fiscales, administrativas y del orden social

${ }^{22}$ A tenor de la Disp. adicional $15^{\mathrm{a}}$. Uno, apdo. 2, el REBECA “estará situado en el territorio de la Comunidad Autónoma de Canarias", precisando la Disp. adicional 15a. Dos, apdo. 1 que "la gestión y administración del Registro especial (...) se realizará a través de dos oficinas de gestión, (...) una, con sede en Las Palmas de Gran Canaria, y otra, con sede en Santa Cruz de Tenerife, incardinadas en las Capitanías Marítimas de las provincias citadas". La oficina especial del REBECA en Las Palmas de Gran Canaria se encuentra en la Capitanía Marítima de Las Palmas, Edificio de la Autoridad Portuaria, Explanada Tomás Quevedo s/n, del Puerto de la Luz de Las Palmas de Gran Canaria; mientras que la segunda se ubica en la Capitanía Marítima de Santa Cruz de Tenerife, Avenida. Fco. Larroche s/n, de esa ciudad.

${ }^{23}$ Sobre el particular, conviene reseñar que en 1961 la Asamblea General de las Naciones Unidas estableció un Comité especial (conocido en la actualidad como el Comité Especial de Descolonización o Comité Especial de los 24) encargado de examinar la aplicación de la Declaración sobre la concesión de la independencia a los países y pueblos coloniales [Resolución 1514 (XXV), aprobada por la Asamblea General de la ONU el 14 de diciembre de 1960]. En la actualidad, entre los territorios no autónomos cuya situación supervisa el mencionado Comité no figuran las Islas Canarias y sí, en cambio, los siguientes territorios en los que la metrópoli ha establecido segundos registros: Anguila, Bermuda, Gibraltar, Islas Caimán, Islas Malvinas, Islas Turcos y Caicos, Islas Vírgenes británicas, Montserrat, Pitcairn y Saint Helen. V. la página 
ultraperiférico, en atención al dato geográfico de la lejanía antes señalado. En este sentido, la peculiaridad que presenta el REBECA frente a otros segundos registros europeos similares es que «las islas españolas forman parte integrante del territorio comunitario y a ellas se les aplica el Derecho comunitario, con excepción de la libre circulación de mercancías y normas anejas (legislación aduanera y Política comercial exterior), las Políticas comunes agrícola y de pesca y algunas normas fiscales (IVA e impuestos especiales)» ${ }^{24}$.

Por otra parte, el REBECA reúne las siguientes características: es un segundo registro de carácter público y administrativo ${ }^{25}$, especial, opcional, heterónomo, adicional al Registro Marítimo ordinario y, en atención al objeto registrable, selectivo.

En efecto, el REBECA se presenta como registro especial porque la LPEMM ha querido expresamente sustraer al REBECA del régimen registral ordinario y someterlo a un régimen legal particular o diferenciado: aquel que resulta de la Disposición adicional decimoquinta de la LPEMM, de las ya indicadas medidas legislativas que incentivan su utilización, y, finalmente, de las normas que, para su desarrollo, lleguen a ser aprobadas en el futuro 26 .

Es, evidentemente, un segundo registro opcional, porque la inscripción de los buques en el REBECA tiene, a diferencia de lo que sucede con el Registro Marítimo ordinario, carácter potestativo y no obligatorio. Como estipula la LPEMM, en el REBECA "se podrán inscribir los buques (...) siempre que reúnan los requisitos previstos (...)",27.

$\mathrm{Su}$ carácter heterónomo obedece a que el MdF retiene las competencias para conceder tanto la inscripción como la baja de los buques en el REBECA $^{28}$, sin que su gestión y administración sean independientes de las autoridades marítimas que, en última instancia, tienen la competencia respecto al Registro Marítimo ordinario. Precisamente, conforme al régimen jurídico especial del REBECA, la decisión de

web de la ONU sobre la Descolonización en la dirección URL:
http://www.un.org/spanish/descolonizacion/main.htm.

${ }^{24}$ MARTÍNEZ JIMÉNEZ, ISABEL «Abanderamiento y nacionalidad del buque», en Varios Autores: Estudios de Derecho Marítimo en homenaje a Ricardo Vigil Toledo, José María Bosch Editor, primera edición, Barcelona, 2000, p. 211.

${ }^{25}$ Disp. adicional 15 . Uno, apdo. 3: "El Registro especial (...) es un Registro público de carácter administrativo (...)".

${ }^{26}$ Disp. adicional $15^{\mathrm{a}}$. Uno, apdo. 3: "El Registro especial (...) se regirá por lo establecido en esta disposición adicional y en sus normas de desarrollo".

${ }^{27}$ Disp. adicional $15^{\mathrm{a}}$. Uno, apdo. (cursiva añadida). Además, la Disp. Adicional 15 ${ }^{\mathrm{a}}$. Cuatro, apdo. 2 señala que las Empresas navieras habilitadas para inscribirse en el REBECA “podrán solicitar la inscripción en el Registro especial de aquellos buques que cumplan" (cursiva añadida) los requisitos que la LPEMM establece seguidamente. En este sentido, el profesor Ignacio Arroyo califica justamente el REBECA como registro opcional. ARROYO MARTÍNEZ, IGNACIO: Curso de Derecho Marítimo, cit., p.345,

${ }^{28}$ Ello resulta particularmente de dos disposiciones de la LPEMM. En primer lugar, la Disp. adicional $15^{\mathrm{a}}$. Dos, apdo. 1 nos indica que las dos oficinas insulares de gestión y administración del REBECA están "adscritas al Ministerio de Obras Públicas y Transportes [actual MdF]"; en segundo lugar, la Disp. adicional $15^{\text {a }}$. Dos, apdo. 2 atribuye a ese Ministerio, "en todo caso, (...) las competencias para conceder la inscripción y la baja en el Registro especial, para determinar las características de la dotación de los buques, las inspecciones de los mismos y aquellos otros trámites administrativos que habilitan la normal operatividad de los buques". 
otorgar a los buques inscritos en el Registro especial la patente de navegación y su efectiva expedición corresponden, respectivamente, al MdF y al Director general de la Marina Mercante ${ }^{29}$.

El REBECA es un Registro adicional o, si se quiere, secundario al Registro Marítimo ordinario, porque los buques que cumplan las exigencias legales para ser inscritos en el REBECA deben, en principio, inscribirse en el Registro Marítimo ordinario. No en vano, la LPEMM dispone que este último "tiene por objeto la inscripción de: "los buques abanderados en España...", lo que debe entenderse -por expreso mandato legal- "sin perjuicio de lo preceptuado en la disposición adicional decimoquinta, reguladora del Registro Especial..."30. Hay que colegir, entonces, que como el otorgamiento de la patente de navegación a los buques inscritos en el REBECA habilita a los mismos "para navegar bajo pabellón español", los buques del REBECA son buques abanderados en España que, por consiguiente, deben ser inscritos en el Registro Marítimo ordinario.

Sin embargo, la afirmación no es absoluta puesto que la LPEMM no exige que todos los buques inscritos en el REBECA deban inscribirse también en el Registro ordinario. La LPEMM ha optado por un criterio funcional (el ámbito o tipo de navegación) para determinar si los buques que han accedido al REBECA causan o no baja simultáneamente en el Registro Marítimo ordinario. Un buque inscrito en el Registro Marítimo ordinario se inscribe en el REBECA y tiene por destino exclusivo la navegación exterior o extranacional, será dado de baja en el Registro ordinario ${ }^{31}$ A contrario, para aquellos buques que no realicen de forma exclusiva navegación exterior o extranacional sino que, además, efectúen una navegación de cabotaje (o sólo realicen esta última), el régimen jurídico registral administrativo se desdobla puesto que "será el del Registro ordinario para la navegación de cabotaje y el del Registro especial... para la navegación exterior o extranacional",32.

Esos preceptos legales hacen que los buques que estén inscritos en el Registro ordinario y en el REBECA, dado que además han de inscribirse en el Registro de Bienes Muebles (RBM), estén teóricamente sometidos a un sistema de registro triple, lo que conlleva o puede conllevar una situación de triplicidad registral pues «el contenido de la inscripción registral del REBECA puede entenderse similar al del Registro Marítimo ordinario, si bien carece, por el momento, del correspondiente desarrollo reglamentario y al parecer funciona con arreglo a las instrucciones administrativas internası ${ }^{33}$. Cabe añadir que ese sistema de triple registro no es, en su totalidad, obligatorio porque, una vez que un buque es voluntariamente inscrito en el REBECA si no realiza de forma exclusiva navegación exterior o extranacional sino que, además,

\footnotetext{
${ }^{29}$ Disp. adicional 15a. Tres, apdo. 2: "La patente de navegación de los buques inscritos en el Registro especial será otorgada por el Ministro de Obras Públicas y Transportes y expedida por el Director general de la Marina Mercante".

${ }^{30}$ Artículo 75, apdos. 1 y 5 de la LPEMM.

${ }^{31}$ Disp. adicional decimoquinta, Tres, apdo. 1, párr. primero de la LPEMM: "La inscripción en el Registro especial de buques que realicen exclusivamente navegación exterior o extranacional, supondrá la baja simultánea del Registro a que se refiere el artículo 75 de la presente Ley".

${ }^{32}$ Disp. adicional decimoquinta, Tres, apdo. 1, párr. segundo de la LPEMM.

${ }^{33}$ GABALDÓN GARCÍA, JOSÉ LUIS y RUIZ SOROA, JOSÉ MARÍA: Manual de Derecho de la Navegación Marítima, Marcial Pons Ediciones jurídicas y sociales, S.A., Madrid-Barcelona, 2002, p. 213.
} 
efectúen una navegación de cabotaje, o sólo realiza esta última- debe obligatoriamente inscribirse en el Registro Marítimo ordinario y en el RBM.

Finalmente, atendiendo al objeto susceptible de inscripción, frente al carácter universal del Registro Marítimo ordinario, el REBECA presenta un carácter más bien selectivo, puesto que no todos los buques, embarcaciones o artefactos navales son objetos registrables, sino aquéllos que respondan a un perfil técnico-funcional concreto: el arqueo mínimo de 100 TRB y la aptitud para la navegación con un propósito mercantil. Quedan, por lo tanto, fuera del REBECA los buques con un arqueo inferior al señalado, así como los buques civiles con un propósito no mercantil $\mathrm{y}$, por expreso mandato legal, los dedicados a actividades pesqueras ${ }^{34}$.

En cuanto a su finalidad, el REBECA como segundo registro persigue los objetivos que ya antes expusimos al examinar de forma general los segundos registros. Así, este Registro posibilita la competitividad de la flota mercante y las empresas navieras españolas a través de una serie de medidas homologables a las existentes en Registros similares de países miembros de la UE. En tal sentido, la primera propuesta de creación en el Archipiélago canario de un registro especial coincide en el tiempo con la modificación del régimen jurídico del registro de la Isla de Man y, prácticamente, con la aparición del Registro francés de las Islas Kerguelen (1987).

En efecto, en 1986, el Gobierno de la Comunidad Autónoma Canaria, la ANAVE y la Asociación de Industrias Refineras de Petróleo propusieron la creación en Canarias de un registro especial. Sin embargo, la idea no empezaría a ser asumida hasta finales de 1991, optando, hasta entonces, la administración por «mantener, como un baluarte, la obligación de empleo de tripulantes nacionales, sin comprender que si no existían navieras y buques competitivos en España, esos tripulantes no tendrían empleo» ${ }^{35}$ La idea se concretó en la elaboración de un Proyecto de Ley, presentado en noviembre de 1991 y que, contando con el apoyo de las empresas navieras, suscitó fuertes críticas y oposiciones en el ámbito sindical ${ }^{36}$. Sin embargo, la demora en el establecimiento del REBECA, desde la fecha de la propuesta antes reseñada (1986) hasta su habilitación legal en la LPEMM (1992) y la adopción posterior de las medidas de incentivos fiscales y de seguridad social (1994) ${ }^{37}$ ya referidas, hizo que transcurriesen ocho años durante los que el pabellón español perdió más de 350 buques, cuatro millones de TRB y cerca de doce mil empleos ${ }^{38}$.

\section{2.- Buques, embarcaciones y artefactos navales registrables.}

Si a tenor del Real Decreto sobre Abanderamiento, Matriculación de buques y Registro Marítimo (RDAb 1989), los buques sometidos al régimen de registro lo son

\footnotetext{
${ }^{34}$ Cfr. Disposición adicional decimoquinta, Cuatro, apdo. 2

${ }^{35}$ CARLIER DE LAVALLE, MANUEL: «El Registro Especial de Canarias. Ventajas y situación hoy», cit., p. 7.

${ }^{36}$ GÓMEZ PRIETO, MARÍA TERESA: «Las sociedades de clasificación de buques», Anuario de Derecho Marítimo, vol. XI, 1994, en nota n ${ }^{\circ} 141$, a pie de las pp. 317-318.

37 Sobre tales medidas, v. ROMERO PI, JUAN: "El Registro Especial de buques en la Ley de Modificación del REF", Noticias de la Unión Europea, no 130, noviembre de 1995, pp. 135 y ss.

${ }^{38}$ CARLIER DE LAVALLE, MANUEL: «El Registro Especial de Canarias. Ventajas y situación hoy», cit., p. 7.
} 
"cualquiera que sea su tonelaje, procedencia y actividad", los buques, embarcaciones y artefactos navales susceptibles de ser inscritos en el REBECA son solamente los que reúnan los requisitos fijados por la disposición adicional $15^{\mathrm{a}}$ de la LPEMM. Esto, como ahora veremos, representa una limitación del objeto registral y sirve de fundamento para proclamar el carácter selectivo del REBECA.

Previamente, conviene tener presente cuáles son los sujetos legitimados para solicitar la inscripción en el REBECA: se trata de las empresas navieras que tengan ya sea la propiedad del buque, ya sea su posesión fundada en un arrendamiento financiero del mismo, en un contrato de arrendamiento a casco desnudo o en otro título que lleve aparejado el control de la gestión tanto náutica como comercial del buque ${ }^{39}$. A estas empresas navieras se les exige, además, tener en el Archipiélago canario bien su centro efectivo de control, bien -si tal no fuera el caso- un establecimiento o una representación permanente con los que cumplir las obligaciones y ejercer los derechos derivados de la legislación española y de las normas relativas al REBECA ${ }^{40}$.

Son las empresas navieras que cumplan tales exigencias las que pueden instar la inscripción de los buques que, siendo de su propiedad o posesión, reúnan asimismo las siguientes condiciones, de manera cumulativa, como objetos registrables:

a) Buques civiles, en construcción o ya construidos. De manera que cabe decir que se trata de embarcaciones, plataformas o artefactos flotantes, con o sin desplazamiento, aptos para navegar con un propósito mercantil (excluyendo los destinados a actividades pesqueras), y no afectos al servicio de la defensa nacional ${ }^{41}$.

La Disposición adicional decimoquinta se ha visto afectada por la Ley 53/2002, de 30 de diciembre, que ha reemplazado la referencia a "todo buque civil utilizado para la navegación con un propósito mercantil..." por "todo buque civil apto para la navegación con un propósito mercantil”. En nuestra opinión, esta modificación significa que los buques civiles idóneos o aptos para la navegación con un propósito mercantil, aunque no estén siendo utilizados efectivamente con este propósito, pueden acceder al

\footnotetext{
${ }^{39}$ Sobre los contratos de arrendamiento a casco desnudo, fletamento por tiempo y fletamento por viaje y sus implicaciones en la gestión náutica y comercial del buque, dice el profesor Ignacio Arroyo que «en el arrendamiento a casco desnudo, el arrendador desplaza íntegramente la gestión comercial y náutica del buque al arrendatario. En el fletamento por tiempo, cede únicamente la gestión comercial, reteniendo la dirección náutica y en el fletamento por viaje detenta la gestión comercial y náutica». ARROYO MARTíNEZ, IGNACIO: Curso de Derecho Marítimo, cit., p. 421. La profesora Isabel Martínez en relación a la exigencia del control de la gestión náutica y comercial del buque a efectos de solicitar su inscripción en el REBECA señala que «no pueden solicitar la inscripción [...] las empresas que sólo tengan la condición de fletadoras (por tiempo o viaje) de los buques ». MARTÍNEZ JIMÉNEZ, ISABEL: «Abanderamiento y nacionalidad del buque», cit., p. 214. Sobre el arrendamiento financiero, v. ARROYO MARTÍNEZ, IGNACIO: «Construcciones navales y arrendamientos financieros», Anuario de Derecho Marítimo, vol. XII, 1995, pp. 401 y ss.

${ }^{40}$ Disp. adicional decimoquinta, Cuatro, apdos. 1 y 2.c) de la LPEMM. Como consecuencia de la Ley 53/2002, de 30 de diciembre, de Medidas Fiscales, Administrativas y del Orden Social, ambas disposiciones resultaron modificadas. Así se ha suprimido en el Cuatro, apdo. 1 la exigencia de que las empresas navieras tengan en Canarias el centro efectivo de control de la explotación de los buques. En cuanto al Cuatro, apdo. 2.c), se añade como título de posesión del buque la condición de arrendatario financiero del buque cuya inscripción se solicita.

${ }^{41}$ Cfr. artículo 8.2 y Disp. adicional decimoquinta, Cuatro, apdo. 2.a) de la LPEMM.
} 
REBECA. Lo cual acerca el objeto registral del REBECA al del RRM de 1956, pues este último califica de buque a "cualquier... aparato flotante destinado o que pueda destinarse a servicios de la industria o comercio..." (artículo 146). Lo que debe permitir la inscripción en el REBECA de buques civiles (deportivos, de recreo,...) que pudieran destinarse a una actividad industrial o mercantil, puesto que no se exige que el buque tenga una finalidad lucrativa, de manera que basta con su potencialidad para este fin. En general, las posibilidades de registrar buques y artefactos aumentan con la nueva redacción lo que puede hacer que el REBECA sea más competitivo, unido ello a los menores condicionamientos requeridos de las empresas navieras.

Pero no pueden acceder al REBECA las plataformas fijas, definidas por la LPEMM como "todo artefacto o instalación susceptible de realizar operaciones de exploración o de explotación de recursos naturales marítimos o de destinarse a cualesquiera otras actividades, emplazado sobre el lecho de la mar, anclado o apoyado en él" ${ }^{\prime 2}$.

b) Como requisito técnico, es preciso que las embarcaciones, plataformas o artefactos flotantes antes reseñados tengan un arqueo mínimo de $100 \mathrm{TRB}^{43}$.

\section{c) La dotación de esos buques está sometida a tres exigencias ${ }^{44}$ :}

a') El capitán y el primer oficial deberán ser nacionales españoles ${ }^{45}$. La restricción tiene su sentido puesto que, si se tienen en cuenta los artículos 612 y 627 del C. de c., tanto el capitán como el primer oficial (que reemplaza provisionalmente al capitán) ejercitan, aunque sea de modo ocasional, funciones públicas (de índole registral, de fe pública y de orden público $)^{46}$. Esto concuerda con la previsión inscrita en el párrafo segundo del artículo 77 de la LPEMM, del que a contrario se infiere que no podrán "los ciudadanos de Estados miembros de la Comunidad Económica Europea (...) acceder (...) a los empleos en las dotaciones de los buques que (...) impliquen el ejercicio, aunque

\footnotetext{
${ }^{42}$ Las plataformas fijas así definidas por el artículo 8.4 de la LPEMM quedan excluidas de la noción de buque civil empleada por la Ley, y ello porque hay que entender que el objeto registral del REBECA lo define la disposición adicional decimoquinta de la LPEMM que emplea expresamente la expresión "buque civil”, definida en el artículo 8.2 de la LPEMM.

${ }^{43}$ Disposición adicional decimoquinta, Cuatro, apdo. 2.b) de la LPEMM.

${ }^{44}$ Para el Registro Marítimo ordinario, el artículo 77 de la LPEMM señala que "el número de miembros de la dotación de los buques y sus condiciones de capacitación profesional deben ser las adecuadas [sic] para garantizar en todo momento la seguridad de la navegación y del buque, teniendo en cuenta sus características técnicas y de explotación, en los términos que reglamentariamente se establezcan". En materia de nacionalidad, no contiene sin embargo una previsión similar a la que rige para el REBECA. El Real Decreto sobre Abanderamiento, Matriculación de buques y Registro marítimo, que de momento es la norma reglamentaria a tener en cuenta no contiene tampoco una exigencia equivalente sobre la nacionalidad del capitán y del primer oficial. Sin embargo, el Código de comercio exige varias condiciones para ejercer el cargo de capitán, entre las que figura la nacionalidad española (párr. primero del artículo 609 del C. de c.).

${ }^{45}$ Disp. adicional decimoquinta, Seis, apdo. a), párr. primero, de la LPEMM.

${ }^{46}$ GABALDÓN GARCÍA, JOSÉ LUIS: «Anotaciones sobre el régimen de policía de la navegación marítima y por agua en el Derecho español», Anuario de Derecho Marítimo, volumen XIII, 1996, nota ${ }^{\circ}$ 138, a pie de la p. 256. El artículo 627 del Código de comercio dispone que "el piloto, como segundo jefe del buque, (...) sustituirá al capitán en los casos de ausencia, enfermedad o muerte, y entonces asumirá todas sus atribuciones, obligaciones y responsabilidades". Respecto a la figura del contramaestre, el artículo 633 establece que "tomará el mando del buque en caso de imposibilidad o inhabilitación del capitán y piloto, asumiendo entonces sus atribuciones y responsabilidad"
} 
sólo sea de manera ocasional, de funciones públicas (...)". Cabría añadir que el Código civil. atribuye al capitán o al que haga sus veces la autorización de testamentos abiertos o cerrados otorgados a bordo de los buques mercantes durante el viaje marítimo, así como su custodia $^{47}$. El C.c. habilita al capitán de una nave a autorizar el matrimonio de quien se halle en peligro de muerte ${ }^{48}$.

Todo ello justifica suficientemente la reserva exclusiva de tales puestos a los nacionales españoles, inclusive a la luz del Derecho comunitario, pues el Tratado CE contempla, como excepciones a la libre circulación de trabajadores, los casos de empleos en la administración pública y las limitaciones justificadas por razones de orden público, seguridad y salud pública ${ }^{49}$.

b') Al menos el 50\% del resto de la tripulación deberá ser de nacionalidad española o de la de cualquier Estado miembro de la UE. Por lo tanto, el otro 50\% de la tripulación podrá tener cualquier otra nacionalidad. Pero el límite del 50\% no es imperativo ya que la LPEMM autoriza al MdF a considerar otras circunstancias (la no disponibilidad de tripulantes de nacionalidad española o de otro Estado miembro de la UE, la existencia de razones de viabilidad económica del servicio de transporte, o cualquier otra causa que pudiera tener una incidencia fundamental en la existencia del servicio) a fin de elevar el porcentaje de tripulantes extracomunitarios, fijándose sin embargo como exigencia ineludible la necesidad de garantizar la seguridad del buque y la navegación ${ }^{50 .}$

${ }^{47}$ Artículo 724 del C.c. Cfr. también el artículo 729 del C.c. para el testamento ológrafo.

${ }^{48}$ Artículo $52.3^{\circ}$ del C.c. Sobre la figura del capitán, sus requisitos, funciones y responsabilidad, v., entre otros: GABALDÓN GARCÍA, JOSÉ LUIS y RUIZ SOROA, JOSÉ MARÍA: Manual de Derecho de la navegación Marítima, cit., pp. 345-369; ARROYO MARTÍNEZ, IGNACIO: Curso de Derecho Marítimo, cit., pp. 314-325; GONZÁLEZ-LEBRERO, RODOLFO A.: Curso de Derecho de la Navegación, Servicio Central de Publicaciones del Gobierno Vasco, Vitoria-Gasteiz, 1998, pp. 299-320.

${ }^{49}$ Artículo 39.3 y 39.4 del Tratado CE. Dichas excepciones han sido objeto de interpretación restrictiva por el TJCE que ha interpretado ampliamente las libertades fundamentales comunitarias y restrictivamente las excepciones o limitaciones. Así, el concepto de Administraciones públicas no está suficientemente precisado ni en el tratado ni en el Derecho derivado. El TJCE ha optado por un criterio material o funcional a la hora de determinar si nos encontramos ante un empleo en la Administración pública, analizando la naturaleza del trabajo o la actividad, no así el vínculo institucional u orgánico con la Administración, para saber si el acceso puede ser excluido a nacionales de otros Estados miembros. La Comisión, por su parte adoptó una Comunicación sobre libre circulación de los trabajadores y el acceso a los empleos en la Administración pública de los Estados miembros (DO C 72 de 18.03.1988), la cual recoge y asume la jurisprudencia y los criterios del TJCE. En ella se consideran cuáles son los sectores de la Administración pública a los que podría ser aplicable la exclusión del artículo 39.4 del tratado CE y cuáles otros se encuentran en principio sujetos al régimen general de libre circulación. Así se consideran funciones específicas del Estado los empleos en las fuerzas armadas, fuerzas de orden público, magistratura, administración fiscal, diplomacia, empleos en las administración que conlleven actividades de poder jurídico público (como la elaboración de actos jurídicos). A sensu contrario, no podrían beneficiarse de la exclusión los empleos en organismos responsables de servicios comerciales (como el transporte, navegación aérea, correos, radiodifusión), los servicios operativos en la sanidad pública, la enseñanza y la investigación en centros públicos; puesto que en éstos las actividades pueden ser desempeñadas sin el requisito de la nacionalidad, ya que se realizan igualmente en el sector privado. VALLE GÁLVEZ, J. ALEJANDRO DEL: «La libre circulación de trabajadores», en LÓPEZ ESCUDERO, MANUEL y MARTÍN Y PÉREZ DE NANCLARES, JOSÉ (coordinadores): Derecho comunitario material, Madrid, 2000, pp. 101-103.

${ }^{50}$ Disp. adicional decimoquinta, Seis, apdo. a), párrs. segundo y tercero, de la LPEMM. 
c') Antes de formalizar la matrícula del buque en el REBECA, el MdF fijará la tripulación mínima del mismo, teniendo en cuenta factores tasados (tipo del buque, grado de automatización y tipo de tráfico al que esté destinado), si bien la resolución que adopte el MdF deberá respetar las exigencias mínimas en materia de seguridad del buque y de la navegación y los tratados internacionales suscritos por España. Para ello será necesario que la empresa naviera presente la solicitud de inscripción de registro del buque en el REBECA ${ }^{51}$.

d) En cuanto a la clase de navegación, la LPEMM exigió en un principio que los buques inscritos estuviesen destinados de manera exclusiva a la navegación exterior o extranacional, si bien paralelamente delegó en el Gobierno la posibilidad de habilitar por R.D. la futura incorporación al REBECA de los buques que realizasen navegación de cabotaje ${ }^{52 .}$ Haciendo uso de esta posibilidad, el Gobierno adoptó sucesivos reales decretos que facilitaron la inscripción en el REBECA de buques destinados a distintos tipos de cabotajes, hasta llegar al R.D. 2221/1998, que ha establecido un régimen definitivo de acceso al REBECA de los buques que realicen navegación de cabotaje ${ }^{53}$. Este R.D. ha permitido además, la inscripción en el registro especial de los remolcadores de altura, previamente inscritos en el Registro Marítimo ordinario a que se refiere el RDAb y siempre y cuando no realicen remolque portuario ${ }^{54}$. Por ultimo, se admiten los tráficos destinados a servicios de crucero. En definitiva, la inscripción de empresas y buques en el Registro Especial permite realizar navegación exterior o extranacional, navegación de cabotaje o uno y otro tipo de navegación (navegación combinada).

e) Únicamente a los buques procedentes de otros Registros y que soliciten su inscripción en el REBECA se les somete a una obligación adicional, consistente en justificar el pago de los tributos de aduanas (caso de buques importados de procedencia

\footnotetext{
${ }^{51}$ Disp. adicional decimoquinta, Seis, apdo. b) de la LPEMM.

52 Disp. adicional decimoquinta, Cinco, de la LPEMM: “1. Se podrán inscribir en el Registro especial los buques (...) cuando se destinen a navegación exterior o extranacional. 2. A la vista del proceso de liberalización de la navegación de cabotaje determinado en el marco comunitario europeo, el Gobierno podrá permitir, mediante Real Decreto, la inscripción en el Registro especial de los buques que se destinen a navegación de cabotaje (...)".

${ }^{53}$ Esos R.D. fueron precedidos del Reglamento comunitario 3577/92, del Consejo, de 7 de diciembre, por el que se aplica el principio de libre prestación de servicios a los transportes marítimos dentro de los Estado miembros (cabotaje marítimo). Primeramente, el Gobierno dictó el R.D. 897/1993, de 11 de junio que permitía el acceso al REBECA de las empresas y buques que realicen navegaciones de cabotaje peninsular de mercancías, con excepción del petróleo, productos derivados del petróleo y agua potable, así como servicios de crucero. Posteriormente, el R.D. 392/1996, de 1 de marzo, reguló el acceso al REBECA de buques destinados a navegaciones de cabotaje para el transporte de petróleo, productos derivados del petróleo y agua potable. Finalmente, el citado R.D. 2221/1998 de 16 de octubre, que pretende fijar, frente al régimen de transitoriedad de los dos R.D. anteriores, un régimen definitivo de acceso de todos las empresas y los buques que realicen navegación de cabotaje al REBECA. En su disposición derogatoria única se previó la derogación, al 1 de enero de 1999, de los anteriores R.D.

${ }^{54}$ El artículo 1.2 del R.D. 2221/1998, de 16 de octubre, establece que podrán inscribirse en el Registro Especial los remolcadores de altura, que estén inscritos en la Lista primera (donde se registran las plataformas de extracción de productos del subsuelo marino, los remolcadores de altura, los buques de apoyo y los dedicados al suministro a dichas plataformas que no estén registrados en otra lista), o en la octava (donde se registran los buques y embarcaciones pertenecientes a organismos de carácter público tanto de ámbito nacional como autonómico o local), correspondiente al Registro Marítimo ordinario a los que hace referencia el artículo 4 RDAb.
} 
extracomunitaria), así como el cumplimiento de las normas de seguridad establecidas por la legislación española y por los convenios internacionales suscritos por España ${ }^{55}$.

Ello explica que el régimen especial del REBECA contemple la posibilidad de una inspección previa a su inscripción en el mismo, en las condiciones que determine el MdF. Esto habrá de efectuarse conforme al Reglamento de Inspección y Certificación de Buques Civiles (RICb) ${ }^{56}$, que se ocupa precisamente de la inspección y control de buques procedentes de otros registros para su abanderamiento en España, previendo un régimen diferente según que el buque proceda del registro de un Estado perteneciente, o no, al Espacio Económico Europeo. Debe, además, entenderse que la construcción en el extranjero de buques destinados a enarbolar pabellón español a través de su inscripción en el REBECA, quedan también sometidos al régimen específico de inspección y control diseñado igualmente en el RICb.

Sin embargo, en esta materia, el RICb ha tenido en cuenta la prioridad del Reglamento comunitario 613/91 relativo al cambio de registro de buques dentro de la $\mathrm{CE}(\mathrm{RCRb})$, que es de aplicación tanto si se pretende la inscripción del buque importado en el Registro Marítimo ordinario como en el REBECA ${ }^{57}$. Pero no es de aplicación sino a los buques que reúnan los requisitos exigidos cumulativamente por el artículo 2 del $\mathrm{RCRb}$, en materia de TRB, antigüedad, pabellón enarbolado, registro nacional de

\footnotetext{
${ }^{55}$ Disp. adicional decimoquinta, Cuatro, apdo. 2. d) y apdo. 3 de la LPEMM.

${ }^{56}$ Este Real Decreto entró en vigor el 28 de febrero de 2001, y se ha visto afectado por la Orden $3479 / 2002$, de 27 de diciembre por la que se regula la firma y visado de documentos a que se refiere el señalado Real Decreto (BOE n ${ }^{\circ} 22$, de 25 de enero de 2003, p. 3291), así como, por el Real Decreto 90/2003 de 24 de enero, sobre reglas y estándares comunes para las organizaciones de inspección y control de buques y para las actividades correspondientes de la Administración marítima. Su objeto es establecer un marco normativo específico que regule las condiciones generales y el procedimiento para la realización de las inspecciones y controles de los buques indicados en el artículo 86.5 de la LPEMM (de todos los buques civiles españoles, de los que se hallen en construcción en España y de los extranjeros en los casos autorizados por los acuerdos internacionales). Según el artículo 3.1, el RICb será de aplicación a la flota civil española que se define en el artículo 2.B.6 como "el conjunto formado por la flota mercante nacional, la flota pesquera nacional, los buques de recreo y deportivos nacionales y los demás buques civiles españoles no incluidos en los supuestos anteriores, según queda definida en el artículo 7 de la Ley de Puertos del Estado y de la Marina Mercante". Quedan incluidos en el ámbito de aplicación del RICb los siguientes buques: a) Los que estando en proceso de construcción en el extranjero, soliciten su abanderamiento bajo pabellón español. b) Los que enarbolando pabellón extranjero se encuentren en aguas situadas en zonas en las que España ejerce soberanía, derechos soberanos o jurisdicción, con las limitaciones que establezca el Derecho internacional, en particular en lo que se refiere a los supuestos de inmunidad. c) Los buques, independientemente del pabellón que enarbolen o vayan a enarbolar, que se hallen en construcción, transformación o reforma en España.

${ }^{57}$ El Reglamento 613/91 del Consejo, de 4 de marzo de 1991, relativo al cambio de registro de buques dentro de la CE (que se ha visto afectado por Reglamento 2099/2002 del Parlamento Europeo y del Consejo, de 5 de noviembre de 2002, por el que se crea el Comité de seguridad marítima y prevención de la contaminación por los buques (COSS) y se modifican los reglamentos relativos a la seguridad marítima y a la prevención de la contaminación por los buques), permite excluir ciertos requisitos de inspección técnica y de certificación a los buques reconocidos y certificados por la administración marítima del país de origen, con la finalidad de promover el establecimiento y el funcionamiento del mercado interior, mediante la eliminación de las barreras técnicas a la transferencia de buques entre los registros nacionales de los Estados miembros, lo que a su vez, permite evitar costes y trámites administrativos a los armadores europeos. Además, conlleva una mejora de la competitividad y condiciones de explotación de los transportes marítimos dentro de la Comunidad, sin perder de vista la necesidad de garantizar un alto nivel de seguridad de los buques y de protección del medio ambiente, con arreglo a los convenios internacionales.
} 
procedencia y certificados válidos ${ }^{58}$. Si concurrieran estas exigencias, el RCRb prohíbe a los Estados donde se pretende el registro del buque importado (en nuestro caso, tanto si se trata del REBECA como del Registro Marítimo ordinario), oponerse a dicho registro 59 .

f) Finalmente, el régimen del REBECA contempla solamente el abanderamiento provisional de buques de pabellón extranjero en el Registro especial canario, pero no la hipótesis inversa, esto es, la del abanderamiento provisional de buques del REBECA en el extranjero. Si se solicitara en el REBECA dicho abanderamiento provisional, no se exige al titular del buque que presente la certificación de baja en el Registro nacional de procedencia $^{60}$. Obsérvese que la disposición adicional decimoquinta exime de la "presentación" de esta certificación, debiendo entender que la baja en el Registro marítimo de origen deberá producirse, pues por principio hay que descartar la posibilidad de que subsista el abanderamiento del buque en dos registros estatales diferentes, cosa prohibida por las disposiciones de la Convención de las Naciones Unidas sobre el Derecho del Mar ${ }^{61}$. Además, es obvio que la no presentación de esa certificación rige sólo para el abanderamiento provisional en el REBECA, no en el Registro Marítimo ordinario, a pesar de que la norma aplicable dice que "no se les exigirá la presentación del certificado de baja (...) para el abanderamiento provisional en España”.

\section{3.- Contenido y efectos de la inscripción}

\footnotetext{
${ }^{58}$ Artículo 2 del RCRb: "El presente Reglamento se aplicará a los buques mercantes cuyo registro bruto sea igual o superior a 500 toneladas y que:

a) hayan sido construidos el 25 de mayo de 1980 o posteriormente, o construidos antes de esa fecha, pero:

- cuya conformidad con las normas relativas a nuevos buques definidas en el Convenio SOLAS de 1974 y, además,

- para los buques cisterna para productos químicos y para el transporte de gas, cuya conformidad con las normas de los códigos contemplados en la letra c) del artículo 1 para los buques construidos el 25 de mayo de 1980 o posteriormente, haya sido Certificada por o en nombre de un Estado miembro, y

b) enarbolen el pabellón de un Estado miembro, estén registrados en éste y lleven en servicio activo bajo ese pabellón desde hace al menos seis meses, y

c) estén provistos de certificados válidos".

Para un examen detallado del RCRb, v. especialmente MORRAL SOLDEVILA, RAMÓN: «El cambio de Registro de Buques en la CEE», Anuario de Derecho Marítimo, vol. X, 1993, pp. 427 y ss.

59 Artículo 3 del RCRb: "1. Los Estados miembros no se opondrán, por razones técnicas derivadas de los convenios, al registro de un buque mercante registrado en otro Estado miembro que cumpla los requisitos y esté provisto de certificados válidos y que disponga de equipos que hayan sido objeto de autorización u homologación en el país de origen del buque...".

${ }^{60}$ Disp. adicional decimoquinta, Tres, apdo. 4 de la LPEMM. V. MARTÍNEZ JIMÉNEZ, ISABEL: «Abanderamiento y nacionalidad del buque», cit., p. 214.

${ }^{61}$ Se trata de dos disposiciones de la Convención de las Naciones Unidas sobre el Derecho del Mar (1982). El artículo 92 señala que “1. Los buques navegarán bajo el pabellón de un solo Estado (...). 2. El buque que navegue bajo los pabellones de dos o más Estados, (...) podrá ser considerado buque sin nacionalidad". El artículo 110 permite a un buque de guerra ejercer el derecho de visita en alta mar sobre un buque que enarbole pabellón extranjero cuando tenga motivos razonables para sospechar que dicho buque “(...) d) No tiene nacionalidad; o e) Tiene en realidad la misma nacionalidad que el buque de guerra, aunque enarbole un pabellón extranjero o se niegue a izar su pabellón”.
} 
Como hemos dicho, el REBECA merece el calificativo de registro especial porque la LPEMM diseñó para el mismo un régimen jurídico distinto del régimen registral ordinario, sometiéndole al régimen legal diferenciado que se establece básicamente en la Disposición adicional decimoquinta, puesto que aún no han sido dictadas las normas reglamentarias para su desarrollo, anunciadas en esa misma disposición adicional ${ }^{62}$.

Transcurridos más de diez años desde la promulgación de la LPEMM, ese retraso en dictar las normas de desarrollo de la Ley explica posiblemente que el funcionamiento práctico se haya dejado a las instrucciones administrativas internas en el seno de la Dirección General de la Marina Mercante (DGMM) y que el contenido de la inscripción efectuada en el Registro especial se asimile o sea equivalente al de los asientos practicados en el Registro Marítimo ordinario, máxime si tenemos presente que el REBECA es, también, un registro público y administrativo y que, además, no funciona de forma independiente (carácter heterónomo) ${ }^{63}$. La común dependencia de los dos Registros de la DGMM y su incardinación en oficinas especiales radicadas en las Capitanías Marítimas de Las Palmas de Gran Canaria y Santa Cruz de Tenerife facilitan, a nuestro entender, la analogía en el contenido de los asientos practicados en uno y otro Registro.

Obviamente, habrán de considerarse en la práctica del asiento registral las especificidades que puedan resultar pertinentes a la luz del régimen jurídico especial del REBECA. Así, por ejemplo, cabe reseñar las siguientes ${ }^{64}$ :

- no será necesario que conste en el asiento el certificado de baja en el registro marítimo de procedencia, en el caso de que se inste el abanderamiento provisional en el REBECA de un buque extranjero;

- podrá figurar la propiedad o bien el título de posesión del buque (en caso de arrendamiento financiero, contrato de arrendamiento a casco desnudo u otro título que lleve aparejado el control de la gestión náutica y comercial del buque)

- acreditar el arqueo mínimo requerido de 100 TRB;

- demostrar que se cumplen los requisitos relativos a la composición mínima de la dotación del buque, o su reducción concedida por el MdF cuando concurran los factores o motivos antes expresados.

Para terminar, en cuanto a los efectos del REBECA, la LPEMM contempla el reconocimiento de la nacionalidad española a los buques inscritos en el mismo, sin que ello difiera sustancialmente respecto al Registro Marítimo ordinario. En efecto, el MdF otorga a los buques inscritos en el REBECA la patente de navegación que, como en el

\footnotetext{
${ }^{62}$ Disposición adicional decimoquinta, Uno, apdo. 3 de la LPEMM.

${ }^{63}$ Como señalan los profesores Gabaldón García y Ruiz Soroa: «el contenido de la inscripción registral del REBECA puede entenderse similar al del DARM [RDAb] (...) y al parecer funciona con arreglo a las instrucciones administrativas internas». GABALDÓN GARCÍA, JOSÉ LUIS y RUIZ SOROA, JOSÉ MARÍA: Manual de Derecho de la navegación Marítima, cit., p. 213.

${ }^{64}$ Disposición adicional decimoquinta, Tres (apdo. 4), Cuatro (apdos. 2.b y 2.c), Seis (apdos. a y b) de la LPEMM.
} 
Registro Marítimo ordinario, permite a los buques del REBECA navegar bajo pabellón español y legitima a los capitanes para ejercer sus funciones a bordo de esos buques ${ }^{65}$.

Quizás cabría añadir que, si el buque inscrito en el REBECA ya lo estaba en el Registro Marítimo ordinario y no causa baja en éste, en realidad la inscripción no supone nada nuevo en cuanto a la adquisición de la nacionalidad, que ya posee. Si causara baja en razón de dedicarse solamente a la navegación exterior o extranacional, mantiene la nacionalidad que tenía, aunque es dado de baja simultáneamente en el Registro Marítimo ordinario, sin que la LPEMM prevea que pierde la nacionalidad para adquirirla nuevamente. Esto sería un contrasentido porque lo que se produce es un cambio entre dos registros nacionales (entre el ordinario y el especial).

Cosa distinta ocurre en los casos de buques en construcción, buques importados o buques de pabellón extranjero para los que se solicita el abanderamiento provisional en el REBECA: en estos casos, la inscripción en el Registro especial tiene efectos constitutivos en cuanto a la adquisición de la nacionalidad española, pues se trata de buques que acceden por vez primera a un registro marítimo español, aunque sea secundario y especial.

Por tanto, el otorgamiento del pabellón español por la vía del REBECA supone la sujeción del buque a la legislación española pertinente, en especial su acogimiento a los derechos e incentivos fiscales, laborales y de seguridad social que han sido previstos para incentivar la utilización del Registro especial canario. La inscripción en el REBECA supone también que el buque queda sometido al control de las autoridades marítimas españolas y que se dé publicidad al contenido de sus asientos.

En cuanto a lo primero, indudablemente, los buques del REBECA están sujetos a las competencias en materia de seguridad y de prevención de la contaminación. Así, el $\mathrm{RICb}$ les es de aplicación, en lo que respecta a las inspecciones y controles iniciales y regulares, que cubren toda la vida del buque, con las excepciones señaladas para los casos de buques comunitarios que cambien de registro de acuerdo con el RCRb. Nada impide, además, que los buques mercantes inscritos en el REBECA puedan también ser objeto de la imposición de las obligaciones de servicio público a las que se refiere el artículo 83 de la LPEMM, o bien sancionados por la comisión de cualquiera de las infracciones previstas en esta Ley.

Aparte del control, el REBECA cumple igualmente con la finalidad de dar publicidad al contenido de sus asientos, lo cual es inherente a la existencia de todos los registros. En este sentido, la disposición adicional decimosexta de la LPEMM, que regula las tasas debidas por las diversas actuaciones registrales, ordena su aplicación también al REBECA, que, por consiguiente, expide igualmente certificaciones y copias de las hojas de asiento, así como copias simples del contenido de los expedientes. Pueden, entonces, predicarse del REBECA los principios de publicidad obligatoria,

${ }^{65}$ Disposición adicional decimoquinta, Tres, apdos. 2 y 3 de la LPEMM. 
tracto sucesivo, legalidad registral, titulación pública y publicidad formal y oponibilidad de los actos registrados ${ }^{66}$.

\section{4.- CONCLUSIONES}

El REBECA es el único segundo registro marítimo español de carácter especial, público y administrativo, opcional, heterónomo, adicional al Registro Marítimo ordinario y selectivo en cuanto al objeto registral.

Su finalidad coincide con la que explica la aparición, desde la década de los años ochenta, de los segundos registros nacionales: frenar el éxodo hacia las BdC e invertir la tendencia al mejorar la competitividad de la flota mercante y las empresas navieras españolas (reducción de costes e incentivos diversos).

Tras la modificación operada en diciembre de 2002 en la LPEMM el objeto de registro en el REBECA se ha ampliado, y por ello, al sustituir las palabras "utilizado efectivamente para una navegación con propósito mercantil" por "apto para una navegación con propósito mercantil" ya no se exige que el buque inscrito tenga una finalidad lucrativa, de manera que basta con su potencialidad para este fin. Así que podrían incluirse como objeto de registro las embarcaciones deportivas o de recreo, como ocurre en el MAR (segundo registro de Portugal). En general, las posibilidades de registrar buques y artefactos aumentan con la nueva redacción lo que puede hacer que el REBECA sea más competitivo, unido ello a los menores condicionamientos requeridos a las empresas navieras.

Finalmente, en cuanto a las consecuencias de la inscripción en el REBECA, en los casos de buques que acceden por vez primera a un registro marítimo español (buques en construcción, buques importados o buques de pabellón extranjero para los que se solicita el abanderamiento provisional), la inscripción en el Registro especial tiene efectos constitutivos en cuanto a la adquisición de la nacionalidad española.

\section{BIBLIOGRAFÍA CITADA}

ARROYO MARTÍNEZ, IGNACIO: «Construcciones navales y arrendamientos financieros», Anuario de Derecho Marítimo, vol. XII, 1995, pp. 401 y ss. ARROYO MARTÍNEZ, IGNACIO: «Reflexiones en torno a la Ley de Puertos del Estado y Marina Mercante», Anuario de Derecho Marítimo, volumen XI, 1994, pp. 21 y ss. ARROYO MARTÍNEZ, IGNACIO: Curso de Derecho Maritimo, J. M. Bosch Editor, Barcelona, 2001. BERLINGIERI, FRANCESCO: «The new Italian international ship

${ }^{66}$ Para un análisis más exhaustivo de esta cuestión véase DOMÍNGUEZ CABRERA, MARÍA DEL PINO: El Registro de Buques, Tesis Doctoral, Universidad de Las Palmas de Gran Canaria, Las Palmas de Gran Canaria, 2002, pp. 442 y ss. 
register», Lloyd's Maritime and Commercial Law Quarterly, Part 4, November 1998, pp. 535 y ss. CARLIER DE LAVALLE, MANUEL: «El Registro Especial de Canarias. Ventajas y situación hoy», Asociación de Navieros Españoles, Ponencia del Director General de ANAVE, Tenerife, 26-28 de septiembre de 2002 (extraído de la página web de ANAVE, dirección URL: http://www.anaves.es/Informes), pp. 1-28. DOMÍNGUEZ CABRERA, MARÍA DEL PINO: «El concepto de buque en el Derecho positivo español», Revista de Ciencias Jurídicas de la Universidad de Las Palmas de Gran Canaria, número 5, 2000, pp. 91 y ss. DOMÍNGUEZ CABRERA, MARÍA DEL PINO: El Registro de Buques, Tesis Doctoral, Universidad de Las Palmas de Gran Canaria, Las Palmas de Gran Canaria, 2002, 547 p. DOMÍNGUEZ CABRERA, MARIA DEL PINO: «El buque como objeto del Registro de Bienes Muebles», Noticias Jurídicas, sección de Artículos doctrinales, febrero 2004, en la dirección URL: http://www.noticiasjuridicas.com, 12 p. ENRIQUEZ ROSAS, DAVID: El buque: una introducción al estudio del estatuto jurídico de las embarcaciones, México, 1998. FARTHING, BRUCE y BROWNRIGG, MARK: Farthing on International Shipping, LLP Publisher, Business of Shipping Series, London-Hong Kong, third edition, 1997. GABALDÓN GARCÍA, JOSÉ LUIS: «Anotaciones sobre el régimen de policía de la navegación marítima y por agua en el Derecho español», Anuario de Derecho Marítimo, volumen XIII, 1996, pp. 192 y ss. GABALDÓN GARCÍA, JOSÉ LUIS y RUIZ SOROA, JOSÉ MARÍA: Manual de Derecho de la Navegación Marítima, Marcial Pons Ediciones jurídicas y sociales, S.A., Madrid-Barcelona, 2002. GONZÁLEZ-LEBRERO, RODOLFO A.: Curso de Derecho de la Navegación, Servicio Central de Publicaciones del Gobierno Vasco, Vitoria-Gasteiz, 1998. GONZÁLEZ LEBRERO, RODOLFO: Manual de Derecho de la Navegación, Buenos Aires, 2000. GÓMEZ PRIETO, MARÍA TERESA: «Las sociedades de clasificación de buques», Anuario de Derecho Maritimo, vol. XI, 1994, pp. 257 y ss. LI, K.X.: «The safety and quality of open registers and a new approach for classifying risky ships», Logistics and Transportation Review, vol. 35E, $\mathrm{n}^{\mathbf{o}} 2$, june 1999, pp. 135 y ss. MARCHESE, UGO: «Funcione economica e politica fiscale del "registro internazionale" italiano di immatricolazione navale», Trasporti. Diritto, Economia, Politica, no 77-78, 1999, pp. 65 y ss. MARTÍNEZ JIMÉNEZ, ISABEL «Abanderamiento y nacionalidad del buque», en Varios Autores: Estudios de Derecho Marítimo en homenaje a Ricardo Vigil Toledo, José María Bosch Editor, primera edición, Barcelona, 2000, pp. 199 y ss. MORRAL SOLDEVILA, RAMÓN: «El cambio de Registro de Buques en la CEE», Anuario de Derecho Maritimo, vol. X, 1993, pp. 427 y ss. ODEKE, ADEMUNI: Bareboat Charter (Ship) Registration, The Hague/London/Boston, 1998. RAY, JOSÉ DOMINGO: Derecho de la navegación, vol. I, Buenos Aires, 1992. READY, N. P.: Ship Registration, LLP Publisher, Business of Shipping Series, London-Hong Kong, third edition, 1998. ROMERO PI, JUAN: "E1 Registro Especial de buques en la Ley de Modificación del REF", Noticias de la Unión Europea, n $^{\circ}$ 130, noviembre de 1995, pp. 135 y ss. SAN JOSÉ AMÉZAGA, JAVIER: «Segundos registros de buques», EIZAGUIRRE, JOSÉ MARÍA DE (Coordinador): $I V$ Jornadas de Derecho Marítimo de San Sebastián (San Sebastián, 23 y 24 de mayo de 1996), Donostia, 1997, pp. 53 y ss. VALLE GÁLVEZ, J. ALEJANDRO DEL: «La libre circulación de trabajadores», en LÓPEZ ESCUDERO, MANUEL y MARTÍN Y PÉREZ DE NANCLARES, JOSÉ (coordinadores): Derecho comunitario material, Madrid, 2000, pp. 95 y ss. 